\title{
Spermine accelerates hypoxia-initiated cancer cell migration
}

\author{
SHINGO TSUJINAKA ${ }^{1}$, KUNIYASU SODA ${ }^{1,2}$, YOSHIHIKO KANO $^{1}$ and FUMIO KONISHI ${ }^{1}$ \\ ${ }^{1}$ Department of Surgery and ${ }^{2}$ Cardiovascular Research Institute, Saitama Medical Center, \\ Jichi Medical University, Saitama-city, Saitama 330-8503, Japan
}

Received August 21,2010; Accepted October 27, 2010

DOI: $10.3892 /$ ijo. 2010.849

\begin{abstract}
Polyamine levels are elevated in the organs and tissues of cancer patients due to increased synthesis and active intercellular transport in cancer cells. Because increased polyamine levels are associated with poor prognosis, the effect of polyamines on the malignant potential of cancer cells was investigated. Highly metastatic colon cancer cells (HT-29) were cultured under either normoxia $\left(21 \% \mathrm{O}_{2}\right)$ or hypoxia $\left(2 \% \mathrm{O}_{2}\right)$ for $48 \mathrm{~h}$ with 0,100 , or $500 \mu \mathrm{M}$ spermine, one of the natural polyamines with the strongest biological activity. Spermine supplementation ameliorated MTT metabolism of hypoxic cancer cells in a dose-dependent manner, but had no effect on cells cultured under normoxia. Hypoxia decreased cancer cell CD44 and E-cadherin expression, while CD44 expression further decreased by spermine in a dose-dependent manner. By comparing cells cultured under normoxia with increasing amounts of spermine, we found that CD44 expression decreased by $11 \%(0 \mu \mathrm{M}$ spermine $), 14 \%(100 \mu \mathrm{M})$, and $18 \%(500 \mu \mathrm{M})$, and was accompanied by comparable decreases in CD44 mRNA levels. Martigel invasion assay showed that hypoxia increased the number of invading cells, and spermine further enhanced the hypoxia-induced increase in the number of invading cells in a dose-dependent manner. The numbers of invading cells cultured with 0,100 , and $500 \mu \mathrm{M}$ spermine under hypoxia were $2.3,2.8$, and 3.2 times greater, respectively, compared to cells with $0 \mu \mathrm{M}$ spermine under normoxia. Increased extracellular spermine enhances the invasion potential of cancer cells under hypoxia.
\end{abstract}

\section{Introduction}

The polyamines, spermine and spermidine, and their precursor, putrescine, are polycations that exist in all mammalian cells (1). They are indispensable for cellular growth and differentiation and are also involved in many physiological functions such as signal transduction and gene expression $(1,2)$. In organs

Correspondence to: Dr Kuniyasu Soda, Department of Surgery, Jichi Medical University, 1-847 Amanumacho, Omiya, Saitama-city, Saitama 330-8503, Japan

E-mail: soda@jichi.ac.jp

Key words: polyamine, spermine, cancer migration, hypoxia, CD44 and tissues where cellular growth is active, such as malignant tumors, intracellular enzymatic activities for polyamine synthesis and polyamine concentration are increased $(1,3)$. In addition to intracellular de novo synthesis, cells can actively transport polyamines from their surroundings, which increases polyamine concentrations in otherwise normal tissues and organs, including blood cells, and urinary excretion of polyamine is often observed in cancer patients (3-5).

Increased polyamine levels in the body and urinary excretions are reported to be associated with enhanced malignant potential $(4,5)$. Because polyamines are essential for cell growth, increased polyamine levels could reflect enhanced tumor cell proliferation. However, factors directly influencing cancer prognosis include the capability of cancer cells to metastasize to distant organs and invade surrounding tissues and organs. Therefore, the effect of polyamines on the metastatic and invasion potential of cancer cells and the factors that promote this potential require investigation.

One example of how cancer cells enhance metastatic potential is provided by the cellular response to hypoxia. In solid tumors such as those in colorectal cancer, there are scattered regions where oxygen delivery is compromised due to diffusion limitations, structural abnormalities of tumor microvessels, and disturbed microcirculation (6). One mechanism by which hypoxia enhances malignant potential is attenuation of cancer cell adhesion through the suppression of adhesion molecule expression $(7,8)$. Adhesion molecules are proteins located on the cell surface that are involved in intracellular binding and binding between cells and the extracellular matrix. Therefore, decreases in adhesion molecule expression can promote cancer cell migration and in turn initiate cancer metastasis and invasion. The adhesion molecule CD44 and E-cadherin are shown to be involved in cancer metastasis and invasion and have decreased expression in response to hypoxia $(9,10)$.

Hypoxia also affects polyamine metabolism by increasing polyamine uptake and concurrently decreasing enzymatic activity needed for polyamine synthesis $(11,12)$. We showed that spermine and spermidine uptake by human peripheral blood mononuclear cells decreases the expression of leukocyte function-associated antigen 1 (LFA-1) and its associated cellular functions in a dose- and time-dependent manner $(13,14)$. Therefore, we hypothesized that in cancer tissues where polyamine concentration is increased, hypoxia-induced increases in polyamine uptake by cancer cells may affect expression of adhesion molecules involved in initiating cancer metastasis and invasion. 
In this study, we selected spermine because previous studies showed that spermine has the most potent effect on LFA-1 expression $(13,14)$. The effects of spermine on factors that initiate cancer metastasis and the invasive potential of cancer cells were investigated.

\section{Materials and methods}

Cell culture and hypoxic exposure. HT-29, a human colorectal carcinoma cell line having potent metastatic ability, was purchased from American Type Culture Collection (Manassas, VA, USA). Cells were routinely grown in Opti-MEM 1 medium (Invitrogen, Carlsbad, CA, USA) supplemented with $5 \%(\mathrm{v} / \mathrm{v})$ heat-inactivated human serum (Hyclone, Logan, UT, USA) and $50 \mathrm{U} / 50 \mu \mathrm{g} / \mathrm{ml}$ penicillin/streptomycin (Invitrogen), at $37^{\circ} \mathrm{C}$ in a humidified atmosphere containing $5 \% \mathrm{CO}_{2}$. In the previous studies, we have shown that spermine $\leq 1 \mathrm{mM}$ is not toxic to cultured cells when cultured in a culture medium supplemented with human serum, but not with bovine serum in which the activities of amine oxidases are found $(13,14)$.

Cells were then seeded in a 6-well culture plate (Corning, Lowell, MA, USA) at a density of $1 \times 10^{5}$ cells $/ \mathrm{cm}^{2}$ and cultured overnight at $37^{\circ} \mathrm{C}$ in a humidified atmosphere containing $5 \% \mathrm{CO}_{2}$. The culture medium was then replenished with either the medium (Opti-MEM 1) alone, or medium supplemented with spermine at a final concentration of 100 or $500 \mu \mathrm{M}$. Cells cultured under normoxic condition $\left(21 \% \mathrm{O}_{2}\right)$ were subsequently cultured in the same condition. For hypoxic exposure $\left(2 \% \mathrm{O}_{2}\right)$, cells were placed in an airtight modulator incubator chamber (Billups-Rothenburg, Del Mar, CA, USA), and hypoxic $\left(2 \% \mathrm{O}_{2}, 5 \% \mathrm{CO}_{2}\right.$, and $\left.93 \% \mathrm{~N} 2\right)$ gas was supplied to the chamber. The chamber was then sealed and placed in an incubator $\left(37^{\circ} \mathrm{C}\right)$. The oxygen concentration in the chamber was monitored with an Oxygen Analyzer (Maxtec, Salt Lake City, UT, USA).

Immunofluorescent staining. Hypoxic exposure of cultured cells was verified using immunofluorescent staining to detect hypoxia-inducible factor-1 (HIF-1 $\alpha$ ) expression. Cells were seeded $\left(1 \times 10^{5}\right.$ cells $\left./ \mathrm{cm}^{2}\right)$ in a Lab-tek II Chamber Slide System (Nunc, Rochester, NY, USA), and cultured under the various conditions mentioned above. Cells were then fixed with $4 \%$ formaldehyde for $20 \mathrm{~min}$. After washing twice with phosphate-buffered saline (PBS) supplemented with $0.05 \%$ Tween-20 (PBS-T), cell permeabilization was performed with PBS containing 0.1\% Triton X-100 (Sigma-Aldrich, Saint Louis, MO, USA). Cells were then washed three times with PBS-T, followed by $1 \mathrm{~h}$ blocking with $1 \%$ bovine serum albumin (BSA) in PBS. The cells were washed twice with PBS-T and incubated overnight $4^{\circ} \mathrm{C}$ with the primary antibody (anti-human HIF-1 $\alpha$, Santa Cruz Biotechnology, Santa Cruz, CA) diluted 1:50 with blocking solution. After three washes with PBS-T, the secondary antibody was incubated with Alexa Fluor 488 conjugated anti-mouse F(ab)'2 fragment IgG (Invitrogen) for $1 \mathrm{~h}$ in the dark. The cells were then washed three times with PBS-T, and a coverslip was mounted using Vectashield Hard Set mounting medium with DAPI (Vector Laboratories, Burlingame, CA, USA). The mounted slide was kept overnight at $4^{\circ} \mathrm{C}$ to ensure complete immobilization, and then examined with a confocal fluorescent microscope (FV500, Olympus, Tokyo, Japan). The observed images were acquired using Fluoview software version 4.3 (Olympus). For a positive control, cells were treated with $150 \mu \mathrm{M} \mathrm{COCl}_{2}$, which mimics the hypoxic response and upregulates HIF- $1 \alpha$ expression (15).

MTT assay. Cell viability and activity were assessed by following the metabolism of 3-[4,5-dimethylthiazol-2-yl]2,5-diphenyltetrazolium bromide (MTT) using the MTT Cell Growth Assay kit (Millipore, Billercia, MA, USA) according to the manufacturer's protocol. Briefly, cells $\left(1 \times 10^{5} \mathrm{cells} / \mathrm{cm}^{2}\right)$ were seeded in a 96-well plate (Corning, Lowell, MA, USA) and cultured in media having serial concentrations of spermine ranging from 0 to $500 \mu \mathrm{M}$ either under normoxic or hypoxic conditions. After culturing for $48 \mathrm{~h}, 10 \mu \mathrm{l}$ MTT reagent was added to each well and the plates incubated for $4 \mathrm{~h}$ at $37^{\circ} \mathrm{C}$. After stopping solution addition, the MTT absorbance was measured with test and reference wavelengths of 570 and $690 \mathrm{~nm}$, respectively, on an ELISA (enzyme-linked immunosorbent assay) plate reader (Titertek Multiskan, Flow Laboratories, McLean, VA, USA). The obtained values were averaged from triplicate readings with the average value of the blank subtracted.

Measurement of polyamine concentration in cancer cells. Cancer cells cultured in various conditions were harvested and washed three times with excess PBS to remove extracellular spermine. Intracellular polyamine concentrations were then quantified by reverse-phase high-performance liquid chromatography (HPLC). Intracellular polyamines were extracted as described previously with some modifications (16). Briefly, a pellet of $1 \times 10^{6}$ cells was sonicated and mixed with $50 \mu 10.6 \mathrm{M}$ perchloric acid. After centrifugation $\left(12,000 \mathrm{x} \mathrm{g}, 10 \mathrm{~min}, 4^{\circ} \mathrm{C}\right)$, the supernatants were collected and kept at $-20^{\circ} \mathrm{C}$ until analysis.

The supernatants $(50 \mu \mathrm{l})$ were mixed with $300 \mu 1$ dansyl chloride $(10 \mathrm{mg} / \mathrm{ml}), 50 \mu 14 \mu \mathrm{M}$ 1,7-diaminoheptane (as an internal standard), and $50 \mu 1$ saturated sodium carbonate solution and incubated for $15 \mathrm{~min}$ at $70^{\circ} \mathrm{C}$. The resulting mixture was then incubated with $25 \mu 1$ proline solution $(100 \mathrm{mg} / \mathrm{ml})$ for $5 \mathrm{~min}$ at $70^{\circ} \mathrm{C}$. Dansylated polyamines were extracted in $500 \mu \mathrm{l}$ toluene and mixed for $30 \mathrm{sec}$. After mixing, the organic phase was removed, dried, and re-dissolved in $500 \mu 1$ acetonitrile. Finally, $10 \mu 1$ sample was injected onto the HPLC system (Shimadzu, Kyoto, Japan), using a Capcell Pak C18 MG column $(4.6 \times 35 \mathrm{~mm}$ internal diameter, $3 \mu \mathrm{m}$ particle size; Shiseido, Tokyo, Japan). The column temperature was set at $50^{\circ} \mathrm{C}$, and the flow rate was $0.9 \mathrm{ml} / \mathrm{min}$ with a twosolvent gradient (solvent A: $55 \% 10 \mathrm{mM}$ ammonium phosphate $+45 \%$ acetonitrile, $\mathrm{pH} 4.4$, solvent B: $100 \%$ acetonitrile). The compounds were detected with excitation and emission wavelengths of 360 and $500 \mathrm{~nm}$, respectively. The data were collected and analyzed using LC Workstation chromatography software (Shimadzu).

Fluorescent activated cell sorting (FACS) analysis. A FACScan flow cytometer (FACSCalibur, Becton-Dickinson) with analysis software (CellQuest) was used for analyses. The following antibodies were used for single-color analysis: FITC-conjugated anti-human CD44, PE anti-CD29, PE anti- 
CD49b, FITC anti-CD25, FITC anti-CD40, and Via-Probe (Becton-Dickinson). Cells cultured in various conditions were detached from the culture plate using cell dissociation buffer (Accutase, Sigma-Aldrich). The collected cells were washed twice with PBS, after which $5 \times 10^{5}$ cells were suspended in PBS with $0.5 \%$ BSA and incubated with each designated antibody (1:50 dilution rate) for $1 \mathrm{~h}$ at $4^{\circ} \mathrm{C}$ in the dark. Negative controls were obtained by substituting the monoclonal antibodies with properly matched isotypes. For the analysis, $1 \times 10^{4}$ cells were gated. Cell viability was assessed using ViaProbe (Becton-Dickinson, Franklin Lakes, NJ, USA) in a manner similar to that mentioned above.

Western blotting. Cells cultured in various conditions were lysed with Cell Lysis Buffer (Epitomics, Burlingame, CA, USA) with $1 \mathrm{mM}$ phenylmethylsulfonyl fluoride (SigmaAldrich) and $20 \mu \mathrm{l} / \mathrm{ml}$ protease inhibitor mix (GE Healthcare, Buckinghamshire, UK) for $5 \mathrm{~min}$ on ice. The lysates were scraped and centrifuged at $14,000 \mathrm{x}$ g for $10 \mathrm{~min}$ at $4^{\circ} \mathrm{C}$. The supernatants were collected and the protein concentration was determined by bicinchoninic acid method using the BCA protein assay kit (Pierce, Rockford, IL, USA).

The protein extracts were boiled at $95^{\circ} \mathrm{C}$ for 3 min with equal amounts of $2 \mathrm{X}$ Laemmli sample buffer. Total protein $(20 \mu \mathrm{g})$ was separated by SDS polyacrylamide gel electrophoresis using a 7.5\%-T gel (Bio-Rad Laboratories, Hercules, CA, USA) and transferred overnight onto Immobilon-P polyvinylidene fluoride membrane (Millipore). After blocking with 5\% non-fat dried milk in TBS-T (50 mM Tris, $150 \mathrm{mM}$ $\mathrm{NaCl}$ with $0.1 \%$ Tween-20) for $1 \mathrm{~h}$, the membrane was incubated overnight at $4{ }^{\circ} \mathrm{C}$ with anti E-cadherin antibody (Becton-Dickinson) diluted 1:500 dilution in TBS-T. A horseradish peroxidase-conjugated anti-mouse IgG (GE Healthcare) diluted 1:5000 in TBS-T was used as a secondary antibody and incubated with the membrane for $1 \mathrm{~h}$. The antibody-bound proteins were detected by enhanced chemiluminescence system (GE Healthcare). The acquired images were scanned and the intensity of each signal was quantified by densitometric analysis software (Image J) provided by the National Institute of Health (USA). $\alpha$-tubulin antibody (Santa Cruz) diluted 1:10000 in TBS-T was used as an internal control.

Real-time reverse transcription polymerase chain reaction. The expression of CD44 mRNA was assessed by real-time reverse transcription polymerase chain reaction (real-time RT-PCR). Isolation of RNA and synthesis of cDNA was performed using the Cells-to- $\mathrm{C}_{\mathrm{T}}$ kit (Ambion, Austin, TX, USA) according to the manufacturer's protocol. Briefly, cells were seeded $\left(1 \times 10^{5}\right.$ cells $\left./ \mathrm{cm}^{2}\right)$ in a 96 -well culture plate (Corning) and cultured as described above. After treatment, lysis solution with DNAase was added to each well. The lysate containing total RNA was collected, and RNA was reverse transcribed to cDNA using RT Enzyme Mix.

For real-time RT-PCR, $100 \mathrm{ng}$ cDNA was used for amplification in a $20-\mu 1$ reaction cocktail with TaqMan Gene Expression Master Mix (Applied Biosystems, Foster City, CA, USA). Glyceraldehyde-3-phosphate dehydrogenase (GAPDH) was used as an internal control. The primer and probe sets were purchased from Applied Biosystems (TaqMan Gene
Expression Assays, Assay ID: Hs00153304_m1 for CD44, and Hs99999905_m1 for GAPDH). The real-time RT-PCR was performed using the 7900 HT Sequence Detection System (Applied Biosystems). The thermal cycling conditions consisted of two holding stages at $50^{\circ} \mathrm{C}$ for 2 min and $95^{\circ} \mathrm{C}$ for $10 \mathrm{~min}$, followed by 40 cycles of $95^{\circ} \mathrm{C}$ for $15 \mathrm{sec}$ and $60^{\circ} \mathrm{C}$ for $1 \mathrm{~min}$. All PCR assays were run in triplicate. The results were analyzed using the SDS software version 2.1 included with the system.

Matrigel invasion assay. To assess the cellular invasive potential, Matrigel invasion assays were performed using the BioCoat ${ }^{\mathrm{TM}}$ Matrigel invasion assay chamber system (Becton-Dickinson) with a membrane with an $8-\mu \mathrm{m}$ pore size. After culturing overnight in serum-free medium (OptiMEM 1), $5 \times 10^{4}$ cells in $0.5 \mathrm{ml}$ of the same serum-free medium were harvested in culture inserts and $0.75 \mathrm{ml}$ of the same medium containing $10 \%$ heat-inactivated human serum was loaded as a chemoattractant to the bottom of each well (24-well companion plate, Becton-Dickinson). After $48 \mathrm{~h}$ of normoxic or hypoxic treatment with or without spermine, non-invaded cells were removed from the insert membranes by cotton swabs. The membrane was mounted onto a slide glass and the invaded cells were then stained using the Diff-Quik staining kit (Sysmex, Kobe, Japan). The number of invaded cells was counted in 10 random fields at magnification x200 in each set of experiments using an inverted microscope.

Statistical analysis. Data are expressed as mean \pm standard deviation (SD). All statistical analyses were performed using SPSS version 11.0 for Windows (SPSS, Chicago, IL, USA). For MTT assay, a correlation between MTT metabolism and spermine concentration was assessed by Pearson's correlation test. Other quantitative data were analyzed by One-way ANOVA test, followed by post hoc Dunnett test. A p $<0.05$ was considered statistically significant.

\section{Results}

Morphological changes and HIF-1 $\alpha$ expression. When compared to the microscopic appearance of cells cultured under normoxia, cells cultured under hypoxia exhibited decreased cell-to-cell contact, loss of polarity, and membranous extension. However, spermine did not seem to affect morphological features either under normoxia or hypoxia (Fig. 1A).

Although HIF-1 $\alpha$ expression was not detected in cells cultured under normoxic conditions, there was strong staining for HIF- $1 \alpha$ in cells cultured under hypoxic conditions $(2 \%$ $\mathrm{O}_{2}$ ) for $48 \mathrm{~h}$ (Fig. 1B). HIF-1 $\alpha$ expression was detected mainly in the nuclei and was comparable to that of cells treated with $150 \mu \mathrm{M} \mathrm{COCl}_{2}$, which served as a positive control. Although hypoxia induced significant HIF-1 $\alpha$ expression, spermine did not affect HIF- $1 \alpha$ expression either under normoxia or under hypoxia.

MTT assay. As shown in Fig. 2, spermine at concentrations of $\leq 500 \mu \mathrm{M}$ did not affect MTT metabolism by cells cultured under normoxic conditions. However, when cells were cultured under hypoxic conditions, spermine increased MTT metabolism. In cells cultured under hypoxic conditions, Pearson's 
A

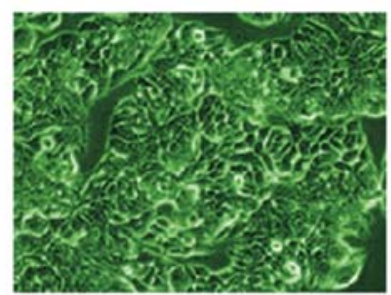

Normoxia $+0 \mu \mathrm{M}$ spermine

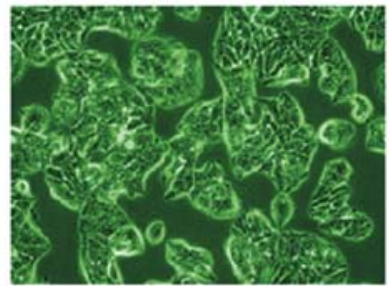

Hypoxia $+0 \mu \mathrm{M}$ spermine

B

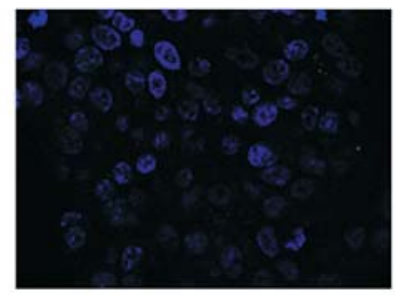

Normoxia

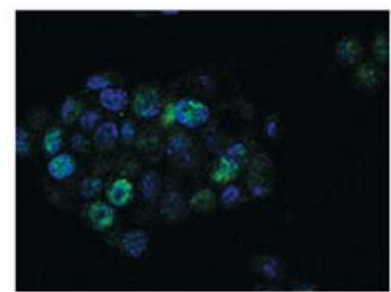

Hypoxia $+0 \mu \mathrm{M}$ spermine

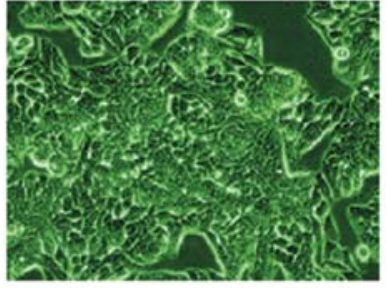

Normoxia $+500 \mu \mathrm{M}$ spermine

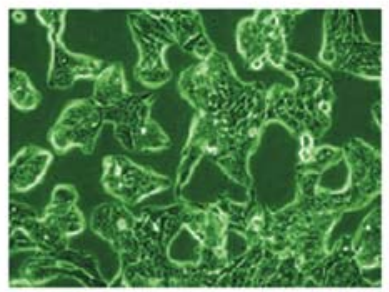

Hypoxia $+500 \mu \mathrm{M}$ spermine

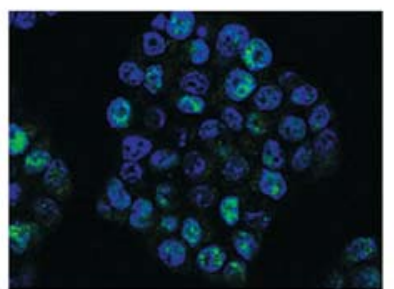

Positive control with $\mathrm{COCl} 2$

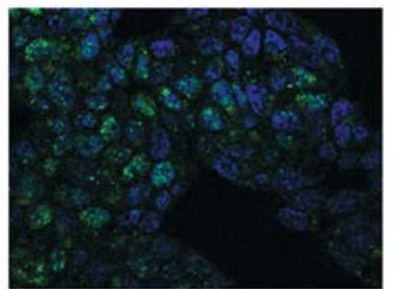

Hypoxia $+500 \mu \mathrm{M}$ spermine

Figure 1. Decreases in cell-to-cell contact, polarity, and membranous extension and level of HIF-1 $\alpha$ expression in response to hypoxia. Cells were cultured under normoxia $\left(21 \% \mathrm{O}_{2}\right)$ or hypoxia $\left(2 \% \mathrm{O}_{2}\right)$ for $48 \mathrm{~h}$ with or without spermine. The images are representative of three independent experiments. (A) Morphological view of HT-29 cells (H\&E staining). Images were captured by inverted microscope (original magnification x 200 ). (B) HIF-1 $\alpha$ expression. Images were captured by confocal fluorescent microscopy (original magnification $\mathrm{x} 60$ ).

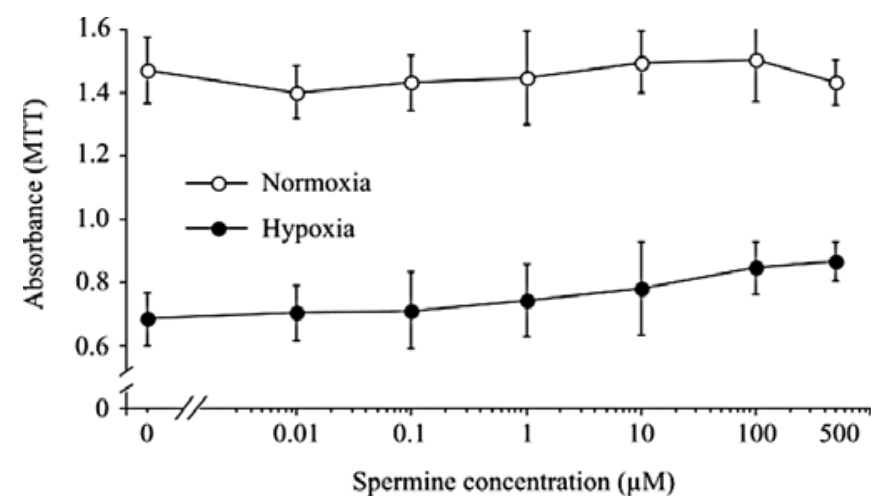

Figure 2. Spermine dose-dependent increases in MTT metabolism by cells cultured under hypoxia. HT-29 cells were plated in 96-well culture plates with 10 serial concentrations of spermine $(0-500 \mu \mathrm{M})$, and cultured either under normoxic $\left(21 \% \mathrm{O}_{2}\right)$ or hypoxic $\left(2 \% \mathrm{O}_{2}\right)$ conditions. After culturing for $48 \mathrm{~h}$, MTT assays were performed in triplicate. Results are expressed as the mean $(n=4)$ with standard deviation $(\mathrm{SD})$. correlation analysis showed a moderate positive correlation between MTT metabolism and spermine concentrations $(\mathrm{r}=0.546, \mathrm{p}=0.001)$. However, no apparent effects of spermine were observed on cells cultured under normoxic conditions $(\mathrm{r}=0.641, \mathrm{p}=0.117)$ (Fig. 2).

Effect of hypoxia and extracellular spermine on intracellular polyamine concentrations. Intracellular spermine concentrations were not affected by either hypoxic treatment alone or supplementation with $500 \mu \mathrm{M}$ spermine under normoxic conditions. However, $500 \mu \mathrm{M}$ extracellular spermine increased spermine concentrations in cells cultured under hypoxic conditions (Table I). Hypoxia without spermine supplementation decreased intracellular spermidine concentrations, and $500 \mu \mathrm{M}$ extracellular spermine decreased spermidine concentrations either under normoxia or hypoxia. Hypoxia seemed to attenuate the decrease in spermidine concentrations induced by extracellular spermine, because spermidine 
Table I. Spermine concentration in normoxia and hypoxia.

\begin{tabular}{|c|c|c|}
\hline & \multicolumn{2}{|c|}{ Extracellular spermine } \\
\hline & $0 \mu \mathrm{M}$ & $500 \mu \mathrm{M}$ \\
\hline \multicolumn{3}{|l|}{ Normoxia } \\
\hline Spermine concentration & $1450 \pm 105$ & $1599 \pm 321$ \\
\hline Spermidine concentration & $333 \pm 58$ & $99 \pm 36^{b}$ \\
\hline \multicolumn{3}{|l|}{ Hypoxia } \\
\hline Spermine concentration & $1549 \pm 356$ & $1811 \pm 276^{a}$ \\
\hline Spermidine concentration & $259 \pm 61^{\mathrm{c}}$ & $165 \pm 47^{b, c}$ \\
\hline \multicolumn{3}{|c|}{$\begin{array}{l}\text { aSignificantly different from cells cultured with } 0 \mu \mathrm{M} \text { spermine } \\
\text { under hypoxia, } \mathrm{p}<0.05 \text {. 'Significantly different from spermidine } \\
\text { concentrations in cells cultured with } 0 \mu \mathrm{M} \text { spermine under the same } \\
\text { oxygen density, } \mathrm{p}<0.01 \text {. 'Significantly different from spermidine } \\
\text { concentrations in cells cultured with corresponding spermine } \\
\text { concentration under normoxia, } \mathrm{p}<0.01 \text {. Intracellular polyamine } \\
\text { concentrations were measured by high-performance liquid chromato- } \\
\text { graphy }(\mathrm{n}=12 \text { ). Results are expressed as the mean value } \pm \mathrm{SD} \\
\text { (pmol } / 10^{6} \text { cells). }\end{array}$} \\
\hline
\end{tabular}

concentrations in cells cultured with $500 \mu \mathrm{M}$ spermine under hypoxia was significantly higher than that of cells cultured with the same spermine concentration under normoxia.

Effects of hypoxia and extracellular spermine on adhesion molecules. The expression of CD44 was decreased (11\%) on cells cultured under hypoxic conditions as compared to normoxic control cells (spermine $0 \mu \mathrm{M}$ ), and its expression was further decreased in a spermine dose-dependent manner (14\% for $100 \mu \mathrm{M}$, and $18 \%$ for $500 \mu \mathrm{M}$ ) (Table II). In contrast, spermine did not affect CD44 expression on cells cultured under normoxic conditions. The effect of spermine under hypoxic conditions was observed only for CD44, as the expression of CD29 or CD49b was not affected either

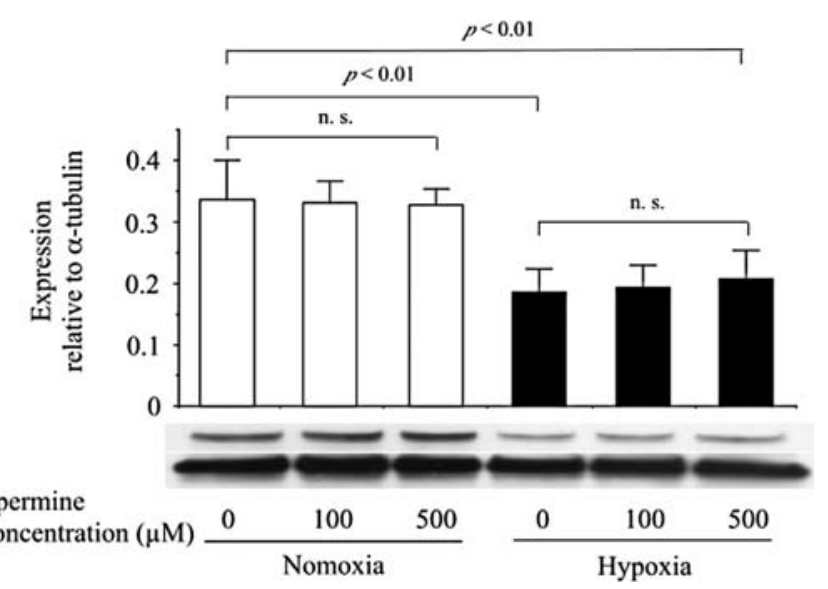

Figure 3. Suppression of E-cadherin expression by hypoxia. The amounts of E-cadherin in lysates of cells cultured under various conditions were measured by Western blotting. The amounts of E-cadherin and $\alpha$-tubulin (as an internal control) were calculated by Image J software. Upper graph, the amounts of E-cadherin are expressed relative to the expression of $\alpha$-tubulin in corresponding cell lysates. The data indicate the mean $\pm \operatorname{SD}(n=7)$. Lower picture, representative data for E-cadherin and $\alpha$-tubulin expression.

by hypoxic exposure and/or spermine. Among membrane molecules examined, CD25 or CD40 were not expressed on HT-29 cells in any of the experimental settings tested.

Cell viability as assessed by Via-Probe indicated that hypoxia resulted in an approximately $11 \%$ decrease in cell viability compared with that of normoxic control $(0 \mu \mathrm{M}$ spermine). Spermine did not affect expression of Via-Probe on cells cultured under either normoxic or hypoxic conditions (Table II).

Unlike CD44, CD29, and CD49, the expression of Ecadherin is greatly affected during cell dissociation, so the amount E-cadherin expression was assessed by Western blotting. E-cadherin expression decreased considerably in cells cultured under hypoxia as compared to those cultured under normoxia. However, spermine did not affect E-cadherin expression under either normoxic or hypoxic conditions (Fig. 3).

Table II. Effects of hypoxia and extracellular spermine on adhesion molecules.

\begin{tabular}{|c|c|c|c|c|c|c|}
\hline \multirow[b]{2}{*}{ Spermine $(\mu \mathrm{M})$} & \multicolumn{3}{|c|}{ Normoxia } & \multicolumn{3}{|c|}{ Hypoxia } \\
\hline & 0 & 100 & 500 & 0 & 100 & 500 \\
\hline CD44 & 100 & $100.7 \pm 11.9$ & $102.2 \pm 8.0$ & $88.9 \pm 8.4^{\mathrm{b}}$ & $86.2 \pm 1.8^{\mathrm{a}}$ & $81.7 \pm 6.5^{\mathrm{b}}$ \\
\hline CD29 & 100 & $101.4 \pm 9.6$ & $97.6 \pm 6.1$ & $105.2 \pm 6.9$ & $103.9 \pm 12.5$ & $103.0 \pm 9.4$ \\
\hline CD49b & 100 & $102.9 \pm 6.2$ & $102.1 \pm 5.7$ & $105.5 \pm 8.8$ & $106.3 \pm 7.2$ & $103.1 \pm 5.7$ \\
\hline Via-Probe & $98.5 \pm 0.5$ & $98.0 \pm 0.6$ & $98.3 \pm 0.4$ & $87.4 \pm 4.4^{b}$ & $88.7 \pm 5.4^{b}$ & $89.9 \pm 2.8^{b}$ \\
\hline
\end{tabular}




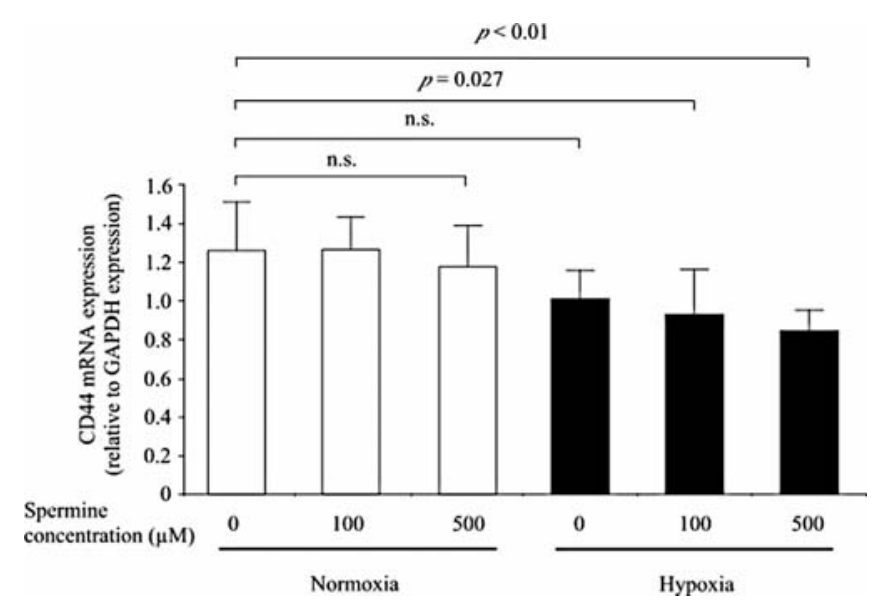

Figure 4. Spermine augments hypoxia-initiated decreases in CD44 mRNA in a dose-dependent manner. CD44 mRNA levels were assessed by realtime RT-PCR. The amount of CD44 mRNA in cells cultured under various conditions for $48 \mathrm{~h}$ is shown relative to that of GAPDH (internal control), and their mean values are shown with SD ( $n=6$, triplicate experiments).

Effect of hypoxia and spermine on the expression of CD44 $m R N A$. Similar to the results of flow cytometric analysis, spermine did not affect CD44 mRNA expression under normoxic conditions. CD44 mRNA levels in cells cultured with $0 \mu \mathrm{M}$ spermine under hypoxic conditions were $20 \%$ lower than those in cells with $0 \mu \mathrm{M}$ spermine under normoxic conditions. Spermine augmented the hypoxia-induced decrease in CD44 mRNA expression in a dose-dependent manner, and its expression in cells cultured with 100 and $500 \mu \mathrm{M}$ spermine under hypoxia was decreased by 26 and $33 \%$ respectively, when compared to that of cells cultured with $0 \mu \mathrm{M}$ spermine under normoxia. As a result, CD44 mRNA expression in cells cultured with 100 and $500 \mu \mathrm{M}$ spermine under hypoxia was significantly lower than that in cells cultured with $0 \mu \mathrm{M}$ spermine under normoxia (Fig. 4).

Effect of hypoxia and spermine on cellular invasive potential. Fig. 5A displays microscopy images of cells in a Matrigel invasion assay for each experimental setting (original magnification $\mathrm{x} 200$ ). The number of invaded cells cultured with $0 \mu \mathrm{M}$ spermine under hypoxia was 2.3 times greater than those with $0 \mu \mathrm{M}$ spermine under normoxia. Spermine increased the number of invaded cells under hypoxic conditions in a dose-dependent manner, while it did not influence the number of invading cells under normoxic conditions. When comparing the number of cells cultured with $0 \mu \mathrm{M}$ spermine under normoxia, the number of migrated cells cultured with 100 and $500 \mu \mathrm{M}$ spermine under hypoxia increased to 2.8 - and 3.2-fold, respectively.

\section{Discussion}

Increases in polyamine in localized parts of the body are reflected in all tissues and organs because polyamines are
A

Normoxia

Hypoxia
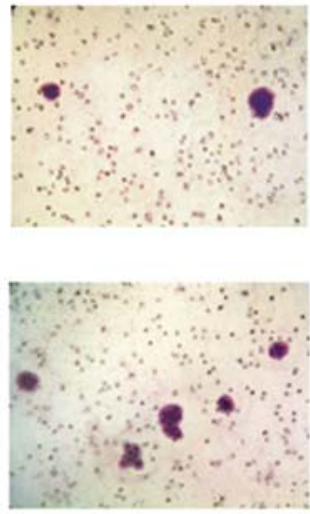

$0 \mu \mathrm{M}$
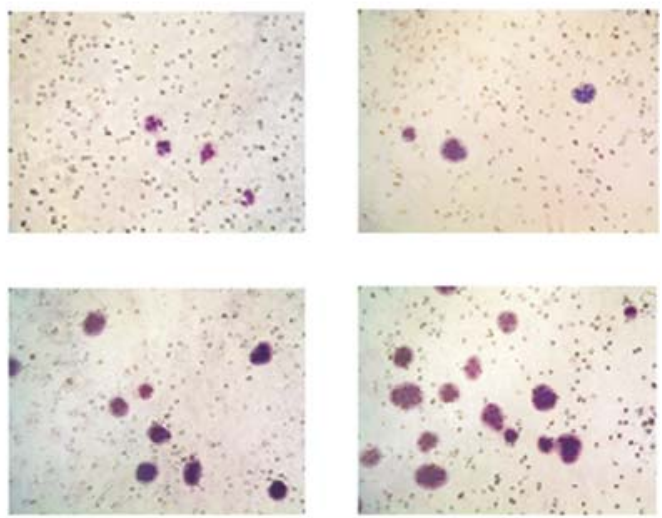

$100 \mu \mathrm{M}$

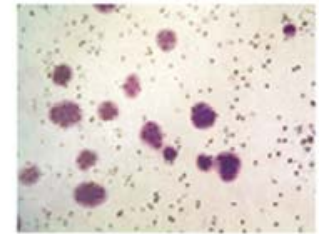

$500 \mu \mathrm{M}$

\section{Spermine concentration}

$p<0.01$

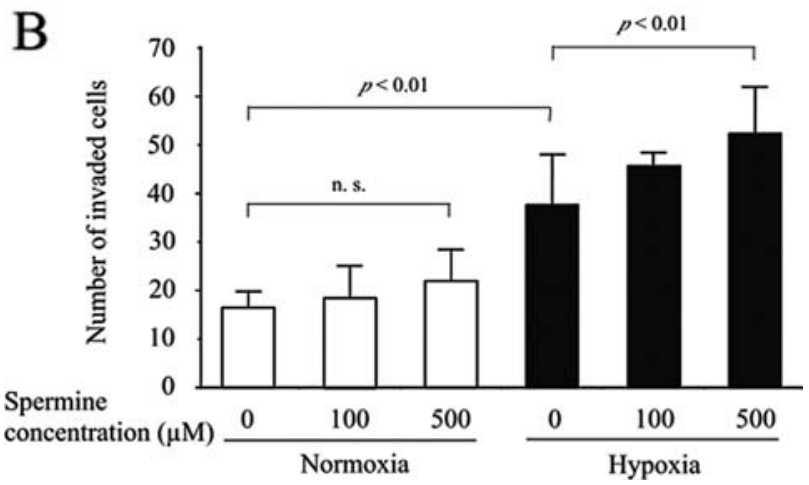

Figure 5. Hypoxia induces HT-29 cell migration and spermine dosedependently increases invasive characteristics under hypoxic conditions. The effects of hypoxia and spermine on cellular invasive potential were assessed by duplicate Matrigel invasion assays. Cells invading through Matrigel were stained and counted in 10 random fields using an inverted microscope (x200). (A) Microscopic images of invaded cells. (B) Number of invaded cells. The data indicate the mean $\pm \operatorname{SD}(n=6)$. 
transferred intercellularly $(5,11,17-19)$. Both cancer cells and non-tumor cells take up polyamines from their surroundings, and the uptake of polyamine, especially spermine, directly affects several cellular functions $(13,14,20)$. In cells exposed to chronic hypoxia, polyamine synthesis is decreased, while the rate of polyamine uptake from cellular surroundings is increased $(21,22)$. Such metabolic alterations induced by hypoxia are reflected in the results of our study, i.e., hypoxiainduced decreases in spermidine concentrations may result from decreased polyamine synthesis, and increased intracellular spermine following extracellular spermine supplementation in hypoxic cells suggests increased polyamine uptake. Moreover, the decreased spermidine concentrations induced by extracellular spermine that are normally observed under normoxic conditions was attenuated by hypoxia, which suggests a dysregulation of hypoxia-induced homeostasis necessary to maintain intracellular polyamine levels.

In cancer tissues, hypoxia is a strong selective pressure that promotes the invasion and metastasis of cancer cells that have a diminished susceptibility to apoptosis. The cellular response to low oxygen tension involves the stabilization of a hypoxia inducible factor-1 (HIF-1) transcriptional complex that activates genes involved in angiogenesis, anaerobic metabolism, cell survival, and invasion (23). Increased intracellular polyamines activate spermidine/spermine $\mathrm{N}^{1}$ acetyltransferase (SSAT), and polyamines act as nitric oxide (NO) donors. Previous studies reported increased SSAT and NO donor levels under hypoxic conditions that seem to promote HIF-1 degradation $(24,25)$. HIF-1 degradation may negatively impact cellular survival, although in this study increased spermine availability under hypoxic conditions did not decrease HIF-1 expression but instead sustained cell viability and maintained proliferation and metabolism of cancer cells exposed to hypoxia. Because polyamines are indispensable for cellular function, survival, and growth, and enhanced polyamine uptake is considered to be essential for solid tumors undergoing hypoxia (18), the beneficial effects of polyamine may overcome specific mechanisms that would impede cellular survival.

Compared to normal epithelia, cancer cells almost invariably have diminished adhesion (26). Intercellular adhesion and the adhesion between the cell and extracellular matrix is regulated by several adhesion molecules such as CD44, E-cadherin, and integrins. Hypoxia suppresses the expression of several adhesion molecules and promotes changes that lead to a malignant phenotype, since reduced expression of these molecules enhances detachment of cancer cells from the primary tumor cluster and contributes to increased invasive potential $(10,27-29)$. As observed in previous reports, we confirmed hypoxia-induced decreases in CD44 and E-cadherin expression by HT-29 cancer cells. However, we did not detect decreases in the expression of integrins, such as CD29 and CD49b, which are known to be decreased by hypoxia (10). One reason why we did not observe decreased expression in these proteins may be because their suppression is only very transient following exposure to hypoxia (10).

In conjunction with hypoxia, spermine specifically augments hypoxia-induced decreases in CD44 expression, and these decreases correlated well with increased migration of HT-29 cells. Reduced CD44 expression is reported to promote cancer metastasis and invasion, allowing detachment of cancer cells from the primary tumor cluster and seems to contribute to the increased migration capacity of hypoxic HT-29 cells $(28,29)$. Because spermine did not induce further suppression of E-cadherin expression in hypoxic cells, spermine seems not to be involved in the mechanisms contributing to hypoxia-induced changes in E-cadherin expression. The mechanisms by which spermine selectively suppresses CD44 as well as the effect of spermine on variant forms of CD44 that have been shown to correlate with increased metastatic potential and poorer prognosis should be further investigated (30-32).

Here we have shown that spermine enhances hypoxiainduced cell migration and decreases CD44 expression of highly metastatic cancer cells. We believe that these results will provide novel insights for the treatment of cancer patients by polyamine restriction, which has been shown to have a favorable impact on the quality of life as well as to promote prolonged survival of tumor-bearing animals (33-35).

\section{Acknowledgements}

This study was subsidized by JKA through its promotion funds from KEIRIN RACE. We have no conflict of interest that we should declare.

\section{References}

1. Gerner EW and Meyskens FL Jr: Polyamines and cancer: old molecules, new understanding. Nat Rev Cancer 4: 781-792, 2004.

2. Childs AC, Mehta DJ and Gerner EW: Polyamine-dependent gene expression. Cell Mol Life Sci 60: 1394-1406, 2003.

3. Russell DH: Clinical relevance of polyamines. Crit Rev Clin Lab Sci 18: 261-311, 1983.

4. Weiss TS, Bernhardt G, Buschauer A, et al: Polyamine levels of human colorectal adenocarcinomas are correlated with tumor stage and grade. Int J Colorectal Dis 17: 381-387, 2002

5. Linsalata M, Caruso MG, Leo S, Guerra V, D'Attoma B and Di Leo A: Prognostic value of tissue polyamine levels in human colorectal carcinoma. Anticancer Res 22: 2465-2469, 2002.

6. Hockel $M$ and Vaupel P: Tumor hypoxia: definitions and current clinical, biologic, and molecular aspects. J Natl Cancer Inst 93: 266-276, 2001.

7. Klymkowsky MW and Savagner P: Epithelial-mesenchymal transition: a cancer researcher's conceptual friend and foe. Am J Pathol 174: 1588-1593, 2009.

8. Pouyssegur J, Dayan F and Mazure NM: Hypoxia signalling in cancer and approaches to enforce tumour regression. Nature 441: 437-443, 2006.

9. Beavon IR: Regulation of E-cadherin: does hypoxia initiate the metastatic cascade? Mol Pathol 52: 179-188, 1999.

10. Hasan NM, Adams GE, Joiner MC, Marshall JF and Hart IR: Hypoxia facilitates tumour cell detachment by reducing expression of surface adhesion molecules and adhesion to extracellular matrices without loss of cell viability. Br J Cancer 77: 1799-1805, 1998.

11. Babal P, Ruchko M, Ault-Ziel K, Cronenberg L, Olson JW and Gillespie MN: Regulation of ornithine decarboxylase and polyamine import by hypoxia in pulmonary artery endothelial cells. Am J Physiol Lung Cell Mol Physiol 282: L840-L846, 2002.

12. Svensson KJ, Welch JE, Kucharzewska P, et al: Hypoxiamediated induction of the polyamine system provides opportunities for tumor growth inhibition by combined targeting of vascular endothelial growth factor and ornithine decarboxylase. Cancer Res 68: 9291-9301, 2008.

13. Soda K, Kano Y, Nakamura T, Kasono K, Kawakami M and Konishi F: Spermine, a natural polyamine, suppresses LFA-1 expression on human lymphocyte. J Immunol 175: 237-245, 2005. 
14. Kano Y, Soda K, Nakamura T, Saitoh M, Kawakami M and Konishi F: Increased blood spermine levels decrease the cytotoxic activity of lymphokine-activated killer cells: a novel mechanism of cancer evasion. Cancer Immunol Immunother 56: 771-781, 2007.

15. Griguer CE, Oliva CR, Kelley EE, Giles GI, Lancaster JR Jr and Gillespie GY: Xanthine oxidase-dependent regulation of hypoxiainducible factor in cancer cells. Cancer Res 66: 2257-2263, 2006.

16. Marce M, Brown DS, Capell T, Figueras X and Tiburcio AF: Rapid high-performance liquid chromatographic method for the quantitation of polyamines as their dansyl derivatives: application to plant and animal tissues. J Chromatogr B Biomed Appl 666: 329-335, 1995

17. Loser C, Folsch UR, Paprotny C and Creutzfeldt W: Polyamines in colorectal cancer. Evaluation of polyamine concentrations in the colon tissue, serum, and urine of 50 patients with colorectal cancer. Cancer 65: 958-966, 1990.

18. Seiler N, Sarhan S, Grauffel C, Jones R, Knodgen B and Moulinoux JP: Endogenous and exogenous polyamines in support of tumor growth. Cancer Res 50: 5077-5083, 1990.

19. Wallace HM and Mackarel AJ: Regulation of polyamine acetylation and efflux in human cancer cells. Biochem Soc Trans 26: 571-575, 1998.

20. Zhang M, Caragine T, Wang $\mathrm{H}$, et al: Spermine inhibits proinflammatory cytokine synthesis in human mononuclear cells: a counterregulatory mechanism that restrains the immune response. J Exp Med 185: 1759-1768, 1997.

21. Tantini B, Fiumana E, Cetrullo S, et al: Involvement of polyamines in apoptosis of cardiac myoblasts in a model of simulated ischemia. J Mol Cell Cardiol 40: 775-782, 2006.

22. Aziz SM, Olson JW and Gillespie MN: Multiple polyamine transport pathways in cultured pulmonary artery smooth muscle cells: regulation by hypoxia. Am J Respir Cell Mol Biol 10: 160-166, 1994.

23. Harris AL: Hypoxia - a key regulatory factor in tumour growth. Nat Rev Cancer 2: 38-47, 2002.

24. Baek JH, Liu YV, McDonald KR, Wesley JB, Zhang H and Semenza GL: Spermidine/spermine N(1)-acetyltransferase-1 binds to hypoxia-inducible factor-1alpha (HIF-1alpha) and RACK1 and promotes ubiquitination and degradation of HIF-1 alpha. J Biol Chem 282: 33358-33366, 2007.
25. Huang LE, Willmore WG, Gu J, Goldberg MA and Bunn HF: Inhibition of hypoxia-inducible factor 1 activation by carbon monoxide and nitric oxide. Implications for oxygen sensing and signaling. J Biol Chem 274: 9038-9044, 1999.

26. Cavallaro U and Christofori G: Cell adhesion and signalling by cadherins and Ig-CAMs in cancer. Nat Rev Cancer 4: 118-132, 2004.

27. Chen J, Imanaka N and Griffin JD: Hypoxia potentiates Notch signaling in breast cancer leading to decreased E-cadherin expression and increased cell migration and invasion. Br J Cancer 102: 351-360, 2010.

28. De Marzo AM, Bradshaw C, Sauvageot J, Epstein JI and Miller GJ: CD44 and CD44v6 downregulation in clinical prostatic carcinoma: relation to Gleason grade and cytoarchitecture. Prostate 34: 162-168, 1998.

29. Kallakury BV, Yang F, Figge J, et al: Decreased levels of CD44 protein and mRNA in prostate carcinoma. Correlation with tumor grade and ploidy. Cancer 78: 1461-1469, 1996.

30. Herrlich P, Pals S and Ponta H: CD44 in colon cancer. Eur J Cancer 31A: 1110-1112, 1995.

31. Gunthert U, Hofmann M, Rudy W, et al: A new variant of glycoprotein CD44 confers metastatic potential to rat carcinoma cells. Cell 65: 13-24, 1991.

32. Wielenga VJ, Heider KH, Offerhaus GJ, et al: Expression of CD44 variant proteins in human colorectal cancer is related to tumor progression. Cancer Res 53: 4754-4756, 1993.

33. Cipolla B, Guilli F and Moulinoux JP: Polyamine-reduced diet in metastatic hormone-refractory prostate cancer (HRPC) patients. Biochem Soc Trans 31: 384-387, 2003.

34. Hogarty MD, Norris MD, Davis K, et al: ODC1 is a critical determinant of MYCN oncogenesis and a therapeutic target in neuroblastoma. Cancer Res 68: 9735-9745, 2008.

35. Quemener V, Moulinoux JP, Havouis R and Seiler N: Polyamine deprivation enhances antitumoral efficacy of chemotherapy. Anticancer Res 12: 1447-1453, 1992. 